\title{
Is it more than allocating funds? Exploring the effect of enterprise crowdfunding on employee engagement
}

\author{
Carina Benz \\ Karlsruhe Institute of Technology \\ carina,benz@kit.edu
}

\begin{abstract}
Enterprise crowdfunding (ECF) has evolved as a novel form to foster innovation and collaboration inside organizations. Research has so far focused on functional aspects related to the introduction of the crowdfunding mechanisms in enterprises (e.g., proposal characteristics or decision-making styles) leaving socio-economic effects on the organization and workforce unexplored. This work investigates the relationship between enterprise crowdfunding and the engagement of participating employees. By conducting an online survey with 321 employees of a multi-national manufacturing and electronics corporation, we find increased levels of employee engagement contingent upon participation in enterprise crowdfunding. These findings contribute to the understanding of effects related to the introduction of crowd-innovation platforms and enterprise social systems. From a practical perspective, they may foster the spread of enterprise crowdfunding as a tool being recognized to promote both, crowd-based innovation and employee engagement.
\end{abstract}

\section{Introduction}

Crowdfunding has become a global phenomenon, using the public to obtain financial support for projects or ventures [1]. Recently, it has increasingly drawn attention among companies and public organizations for its possible application to innovation management [2], [3]. Organizations are experimenting with the in-house usage of the crowdfunding mechanism to drive innovation: In so-called enterprise crowdfunding, they enable employees to fiduciary invest company funds in idea proposals submitted by their co-workers [3], [4]. Hence, ECF can be a means to foster the generation of ideas within the workforce and to tap the wisdom of the employee crowd for deciding upon funding allocation.

Apart from these functional benefits, ECF offers potential to advance corporate culture and foster positive work environments. The platform itself allows users to interact and collaborate, to exchange ideas and to mutually improve projects [5]. Through active participation, the individual employee is given the opportunity to contribute to the organization's success and may feel empowered [6]. Simultaneously, through comments, feedback and improvement suggestions, organizations can tap knowledge from their employees, that goes beyond the decision of budget allocation.

However, the core of research related to (enterprise) crowdfunding still focuses on the idea generation and evaluation mechanism [7]-[10] with little empirical results on ECF's spillover effects on employee behavior and organizational culture. Yet, the hope to improve the socio-economic environment in organizations is explicitly quoted by executives, who promote the introduction of enterprise crowdfunding platforms and related enterprise social systems in their organizations [11]-[13].

Hence, this study aims to contribute to the existing body of knowledge, by concentrating on the effect of enterprise crowdfunding on employee engagement. The concept of employee engagement is broadly defined as the investment of "a person's preferred self" in workrelated tasks, in physical, cognitive and emotional presence, as well as in active role performance [14]. Being connoted with attributes such as passion, enthusiasm, activation and energy, high levels of employee engagement are generally considered as a desirable state for organizations [15]. While the concept is primarily discussed in organizational contexts as general work engagement, it can as well exert a positive impact on innovation and creativity [16]. Employee engagement is, thus, interpreted in the sense that employees are feeling involved and are proactively participating in the company's innovation activities [17]. Hence, we study whether the alteration of environmental conditions in the company triggered by the application of enterprise crowdfunding, has an effect on employees' engagement [15]. This is related to the following research question: How does participation in an enterprise crowdfunding initiative affect employee engagement? 
To explore this effect, we conducted a longitudinal study at a multinational manufacturing and electronics corporation surveying both, participants and nonparticipants of an ECF initiative. Applying a repeated measurement design, data is collected at two points in time (before the ECF event and directly after the ECF event) among a sample of employees pre-registered for the ECF event as well as a control group of unregistered employees. In total, data sets of 321 respondents were analyzed regarding differences and changes in employee engagement.

In doing so, this study contributes to both, theory and practice. From a theoretical perspective, our study contributes to the body of internal crowd-innovation platforms and enterprise social systems by empirically examining their effect on employee engagement. In particular, we advance the understanding of enterprise crowdfunding as a novel tool for innovation management in organizations. From a practical perspective, our study will equip executives with knowledge on the effect of enterprise crowdfunding on some socio-economic factors of organizational innovativeness through hypothesis testing. Ultimately, this can further promote the implementation of enterprise crowdfunding initiatives.

The remainder of this paper is structured as follows: the second section provides conceptual background on enterprise crowdfunding and employee engagement. Section three introduces our hypotheses, while section four elaborates on our approach for empirical investigation. Sections five and six present and discuss our empirical results. A summary of the findings of this study is given in section seven.

\section{Theoretical Background}

This section aims to provide theoretical background and evaluates related work on enterprise crowdfunding and employee engagement.

\subsection{Enterprise Crowdfunding}

Public crowdfunding - an alternative source of funding for entrepreneurs through an open call on the Internet [1] - has become a widely accepted phenomenon within the last years, with correspondingly enhanced activity in academic research [18]-[21]. In crowdfunding, a large audience of private backers - the crowd - is tapped for financial investments in return for potential rewards (e.g., equity shares, non-financial rewards such as goods or services, donations) [1]. Under the term enterprise crowdfunding or internal crowdfunding, the crowdfunding mechanism known from online implementations has started to spread as a tool inside established organizations [2]-[4], [9]. In enterprise crowdfunding employees propose project ideas on an internal crowdfunding platform in which their co-workers can invest with money provided to them by the organization [8], [9], [22]. In this context, employees are endowed with corporate funds, which they can freely invest in projects initiated by their colleagues [9]. Unspent money usually expires after the funding phase and projects cannot collect more money than they initially target [9]. Typically, hierarchical interventions, altering the outcome of the financial distributions, are not intended [4], thus decision rights are handed over to the crowd of employees. Hence, enterprise crowdfunding differs from classical crowdfunding: while public crowdfunding is primarily used to seek financing for startups and small businesses, enterprise crowdfunding is applied by established companies to foster innovation, collaboration and effective evaluation of ideas [3]. Furthermore, employees do not invest private funds, but virtual coins or company budgets [2], [9]. In addition, enterprise crowdfunding is often organized in time-limited events to concentrate attention and activity within the organization [9].

Enterprise crowdfunding is positioned on the intersection of internal crowd-innovation platforms [2] and enterprise social systems [23], [24]. Following the principle of the wisdom of crowds [25], ECF platforms can support innovation management by tapping the creative potential and knowledge of employees outside of the innovation and R\&D departments [2], [9]. In this context, enterprise crowdfunding is similar to an idea contest representing a platform to foster, share and discuss ideas [2], [4]. At the same time, they incorporate characteristics of enterprise social system: they represent a place for employees to share their ideas and express their opinion (e.g., by proposal submission, commenting, liking). As a group activity, it encourages inter-departmental discussion and collaboration [3], [9], [23]. Most research on enterprise crowdfunding has so far focused on either conceptualizing the phenomenon [3], [4], [26] or understanding particularities of ECF in contrast to public crowdfunding [7], [8], [27]. In this regard, proposal characteristics and funding success [8], as well as decision-making [7], [27] have been of certain interest. However, there is a paucity of empirical studies related to the effect of enterprise crowdfunding on the organization and its socio-economic environment [3], [9].

\subsection{Employee Engagement}

The engagement concept was first introduced by Kahn [14] in his investigation of working conditions leading employees to personally engage or disengage. Employee engagement is a psychological state that is 
broadly defined as an "individual's involvement and satisfaction as well as enthusiasm for work" [28]. Hence, engaged employees are described as employing themselves physically, cognitively and emotionally in their job role [14]. They have a sense of energetic and effective connection with their work activities and consider themselves as able to successfully deal with the demands of their job [29]. Moreover, engaged employees work with passion and are willing to drive organizational goals [12]. Consequently, employee engagement is associated with positive organizational outcomes, including increased productivity, higher performance, increased resilience, and generally higher organizational profitability [12], [30].

From a conceptual perspective, Macey and Schneider [15] divide employee engagement into three components: (1) trait engagement, (2) state engagement and (3) behavioral engagement. Trait engagement is regarded as a person's individual disposition and general orientation to experience the world [15]. Hence, trait engagement is an invariant attribute of the employee, similar to personality [12]. High levels of trait engagement are associated with positive views of life and work originating from a proactive and autotelic personality [15]. State engagement as momentary psychological state is associated with feelings of energy and absorption [15], [31]. Hence, satisfaction, involvement, commitment and empowerment are emotional states linked to state engagement [15], [32]. Behavioral engagement reflects the behavioral consequences that follow. Engaged individuals are keen to invest their personal resources beyond the expected demand. Typical engagement behaviors encompass personal initiative, proactivity, role expansion and adaptivity to change [15].

State and behavioral engagement are regarded as temporary states that change across relatively short time periods [12], [31]. Consequently, engagement is fluctuating, representing the reaction to experiences in response to one's environment [15], [30], [32]. As such, work-related experiences, attributes of work, and the perception of leadership are recognized as factors that cause variations in employee engagement [15], [33]. One particular means to foster employee engagement could be the introduction of enterprise crowdfunding as IT-platform that provides new possibility for social exchange and alters traditional innovation and organizational processes [34], [35].

\section{Hypothesis Development}

Although enterprise crowdfunding is gaining in appeal as a tool to foster innovation and idea elaboration, effects on the broader organizational culture and employees' behavior are reported only sparsely [9]. This study aims to investigate how the introduction of and participation in an ECF initiative influences employee engagement.

When considering the effect of an employee's current levels of satisfaction with the organization and working environment on their participation in ECF, controversial findings are discussed in existing literature: Jeppesen and Frederiksen [36] emphasize the role of corporate climate in terms of previously perceived or expected organizational appreciation for employees contribution to innovation communities. Organizational factors, such as top management support, are similarly highlighted by Chin et al. [37] in their investigation of influencing factors for employees' participation in enterprise social networks. This might indicate that low levels of state engagement hinder participation in enterprise crowdfunding. Findings from investigations of enterprise crowdfunding initiatives, however, suggest differently: Muller et al. [9] link participation in ECF to employees' "ability to make real change in employees' work environments, and to satisfy work needs through a channel that was not constrained by corporate expense controls" [9]. One of their interviewees explicitly affirmed that in enterprise crowdfunding he wanted to make a statement and make the organization aware of the things he was missing so far [9]. Hence, employees with low state engagement, who feel less satisfied and empowered, could regard enterprise crowdfunding as opportunity to initiate change. As these observations are specific for enterprise crowdfunding, we will follow Muller et al. [9] and hypothesize that employees deciding to participate in enterprise crowdfunding initiatives exhibit lower levels of state engagement compared to non-participants (H1a).

Similar to related innovation contests and enterprise social systems, participation in enterprise crowdfunding is on a voluntary basis. Hence, the group of participants forms based on self-selection. Furthermore, time and effort invested in enterprise crowdfunding and related internal IT-platforms is typically not compensated or rewarded [3]. On the contrary, employees might have less time for their work assignments or will need to invest their leisure time for participation. This is equivalent to the "extra-role behavior" as in the definition of behavioral engagement (i.e., "innovative behaviors, demonstrations of initiative, proactively seeking opportunities to contribute, and going beyond what is [...] typically expected" [15]. Accordingly, it is suggested that employees deciding to participate in enterprise crowdfunding exhibit higher levels of behavioral engagement ( $\mathrm{H} 1 \mathrm{~b})$ compared to nonparticipants.

Wendelken et al. [38] also find participants in internal innovation communities to be closely connected 
to the company and eager to advance its future and innovativeness. Non-participants report to be less involved and prefer keeping a distance from the company. In general, these are actions performed by positively minded persons that are intrinsically motivated to engage in enterprise crowdfunding [3], [20]. Accordingly, one can assume that employees deciding to participate in enterprise crowdfunding exhibit higher levels of trait engagement (H1c) compared to non-participants.

Summarizing, we formulate the following hypotheses as illustrated in Figure 1 with regards to the effects of employee engagement prior to an enterprise crowdfunding initiative:

H1a: Employees deciding to participate in enterprise crowdfunding initiatives exhibit lower levels of state engagement compared to non-participants.

H1b: Employees deciding to participate in enterprise crowdfunding initiatives exhibit higher levels of behavioral engagement compared to nonparticipants.

H1c: Employees deciding to participate in enterprise crowdfunding initiatives exhibit higher levels of trait engagement compared to non-participants.

Enterprise crowdfunding can improve organizational transparency and flatten hierarchies by offering employees a platform to initiate organizational change in a new way [9]. Through project proposal and funding, employees can articulate and emphasize diverse unmet wishes. Hence, they feel valued, heard and significant to the company's future [39]. One aspect that is particular to enterprise crowdfunding is the conferral of decision-making power. Budget decisions for innovation projects are made bottom-up by the participating employees without veto rights for the management. This allows employees, who would otherwise not be seen as authorities, to have a considerable impact [35]. Hence, ECF contributes to removing hierarchical barriers, which has been positively linked to employee engagement [9], [39]. Consequently, it is suggested that the participation in an enterprise crowdfunding initiative can contribute to enhanced levels of an employee's state engagement (H2a and $\mathrm{H} 3 \mathrm{a}$ ).

The more employees interact with and on enterprise social systems, the more they feel engaged [40]. Men et al. [40] find that "regardless of employees' level of satisfaction with their relationships with the organization, the more employees read the company's and co-workers' posts, interact with the content by liking, sharing, and commenting on the posts, and engage in one-on-one conversations or group discussions on internal social media, the more they feel absorbed, attentive, dedicated, connected, and involved in the organization" [40]. Similar interactions are possible on enterprise crowdfunding platforms. Based on qualitative data, Muller et al. [9] find intensified collaboration and increased community feeling to be particular outcomes of enterprise crowdfunding initiatives. Moreover, it fosters social recognition by leveraging appreciation of peers and management for contributions to the company's innovativeness. Seeing and being recognized for one's impact - e.g., when a project proposal gets funded-can reinforce employees engagement [16], [41]. Hence, the introduction of enterprise crowdfunding platforms can foster appreciative, collaborative and collegial workplace experiences, which may be beneficial for employees' behavioral engagement [35] (H2b and H3b).

Comparing participants and non-participants postECF, we hypothesize that:

H2a: Employees who participated in enterprise crowdfunding exhibit higher levels of state engagement compared to non-participants.

H2b: Employees who participated in enterprise crowdfunding exhibit higher levels of behavioral engagement compared to non-participants.

Following the identical line of argumentation, an increase of employee engagement initiated by the introduction of ECF can be assumed. Hence, we hypothesize that:

H3a: Participants' state engagement increases upon participation in enterprise crowdfunding.

H3b: Participants' behavioral engagement increases upon participation in enterprise crowdfunding.

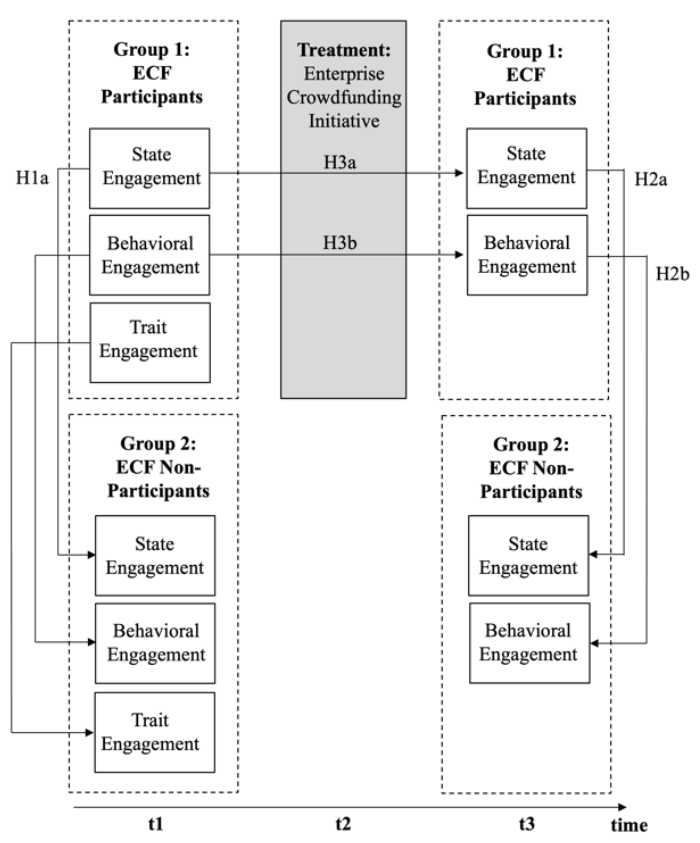

Figure 1. Hypotheses 
Trait engagement, which is conceptualized a stable personal trait, is not expected to change over time and not depending on transformations in an employee's environment. Hence, no hypotheses on the variation of trait engagement contingent upon ECF are proposed. Figure 1 depicts our hypothesis subject to participation and point in time.

\section{Empirical Investigation}

To explore the effect of enterprise crowdfunding on employee engagement, we conducted a longitudinal study based on an online survey with participants and non-participants of ECF. This section provides details on the methodology: We explain the procedure and sample, demonstrate the applied measurement and illustrate the data analysis process.

\subsection{Sample and Procedure}

We conducted our study in the context of an enterprise crowdfunding initiative that took place in a multinational manufacturing and electronics corporation between March and April 2017. The enterprise crowdfunding initiative was organized as a time-limited event and was facilitated by a dedicated crowdfunding platform only accessible on the organization's intranet. The ECF initiative was initiated by the corporate research department and more than 8.000 employees were eligible to participate in the event. Participation in the ECF initiative was voluntary for employees. Hence, interested employees had to register in advance.

The ECF initiative was divided into a two-month registration and idea generation phase, and a three-week funding phase to evaluate the ideas. With the start of the funding phase, the crowdfunding platform was launched. Hence, project proposals were visible, interaction in form of comments and likes was possible, and the funds provided by the organization could be invested by participants. Since there was no thematic restriction on the content of proposals, they covered a range of possible topics. A project proposal contains information on the project plan, the target funding amount and the creator. Also, media such as picture or videos could be included. In total, an equivalent of $\$ 500.000$ of corporate funds that were equally distributed among registered employees were invested in project proposals. The enterprise crowdfunding initiative followed an 'all-or-nothing' principle, i.e., only those proposals that met their pre-defined funding goal were allowed to keep their money and segue into implementation.

Subjects for this study are recruited among the groups of employees participating and not-participating in the ECF event: Links to an online questionnaire were distributed via internal mailing lists to the 375 employees pre-registered for the ECF initiative as well as a control group of 400 randomly selected unregistered employees. This research design allows to control for confounding events during the data collection. Data is collected at two points in time (before the ECF funding phase and directly after the ECF funding phase) to measure the effect of ECF participation. The first questionnaire could be answered in the time frame of three weeks before the funding phase. The second one started directly after the funding phase with a term of three weeks. In total, 208 employees took part in the first survey and 154 in the second, which corresponds to standard response rates of $26.84 \%$ and $19.87 \%$.

\subsection{Measurement}

For the measurement of employee engagement, we follow Macey and Schneider [15], who distinguish between trait engagement, state engagement, and behavioral engagement. Traditional engagement scales (e.g., Utrecht Work Engagement Scale, ISA Engagement Scale) would retrieve engagement only as a compound state without acknowledging differences in continuity and influenceability of the three distinct concepts [31]. Besides, their applicability for the investigation of engagement in innovation contexts is limited due to their focus on general work engagement. Consequently, we relied on a scale based on the Macey and Schneider [15] framework and adapted to the context of this study. Each of their three concepts is initially represented by four items; E.g., state engagement is covered by questions considering satisfaction, involvement, commitment, and empowerment. All items are retrieved with a 5-point Likert-type scale (1='strongly disagree'; 5'strongly agree'). Table 1 provides an overview of the measurement items.

We assessed reliability and validity of the measures with confirmatory factor analysis (CFA). The CFA results for this three-factor model show a reasonably good fit, with $\chi 2=437.43$ (d.f. $=28, \mathrm{p}<0.01)$, CFI $=.97$ and RMSEA $=.06$. All of the factor loadings in the final measurement model are significant in the predicted directions. Cronbach's alphas (CA) and composite reliability (CR) of at least 0.7 suggest good reliability of factors [42]. Validity of the measurement is assessed by the average variance extracted (AVE), which is in an acceptable range between .47 and .58 [42]. Four of the initial twelve items were excluded due to low factor loadings, which improves construct reliability. These are displayed in parenthesis in Table 1. Items are equally weighted aggregated to the corresponding constructs of 
trait engagement, state engagement and behavioral engagement.

Table 1. Measurement items

\begin{tabular}{|c|c|c|c|c|}
\hline Item & $\mathbf{C A}$ & $\mathbf{C R}$ & AVE & FL \\
\hline State engagement & 0.82 & 0.81 & 0.58 & \\
\hline $\begin{array}{l}\text { "I am satisfied with my role in } \\
\text { innovation at company A." }\end{array}$ & & & & 0.76 \\
\hline $\begin{array}{l}\text { "I feel involved in the innovation } \\
\text { processes at company A." }\end{array}$ & & & & 0.81 \\
\hline $\begin{array}{l}\text { ("I am committed to participate in the } \\
\text { innovation process at company A.") }\end{array}$ & & & & $(0.24)$ \\
\hline $\begin{array}{l}\text { "I feel empowered to contribute to } \\
\text { innovation at company A." }\end{array}$ & & & & 0.70 \\
\hline Behavioral engagement & 0.76 & 0.72 & 0.47 & \\
\hline $\begin{array}{l}\text { ("I am inspired to support company A's } \\
\text { community in shaping its future.") }\end{array}$ & & & & $(0.33)$ \\
\hline $\begin{array}{l}\text { "I am eager to go the extra mile for } \\
\text { company A's innovativeness." }\end{array}$ & & & & 0.67 \\
\hline $\begin{array}{l}\text { "I am inspired to perform tasks and } \\
\text { take perspectives outside my normal } \\
\text { working role." }\end{array}$ & & & & 0.73 \\
\hline $\begin{array}{l}\text { "I am willed to incorporate changes } \\
\text { from innovation endeavors (e.g. new } \\
\text { topics, new processes, new working } \\
\text { modes) in my professional role." }\end{array}$ & & & & 0.64 \\
\hline Trait engagement & 0.71 & 0.71 & 0.55 & \\
\hline $\begin{array}{l}\text { "In general, I consider myself a } \\
\text { proactive person in my professional } \\
\text { environment." }\end{array}$ & & & & 0.74 \\
\hline $\begin{array}{l}\text { ("I often perform activities simply } \\
\text { because I like doing them, rather than } \\
\text { for specific gains or rewards.") }\end{array}$ & & & & $\overline{(0.40)}$ \\
\hline $\begin{array}{l}\text { "In general, I consider myself an } \\
\text { enthusiastic person in my professional } \\
\text { environment." }\end{array}$ & & & & 0.75 \\
\hline $\begin{array}{l}\text { ("In general, I consider myself a } \\
\text { conscientious person in my } \\
\text { professional environment.") }\end{array}$ & & & & $(0.48)$ \\
\hline
\end{tabular}

FL: Standardized loadings: all lambdas are significant at $\mathrm{p}<0.01$. Note: Items in parenthesis are excluded due to low FL or CA.

\subsection{Data Analysis}

Cases with more than one missing value were excluded from the analysis. For the remaining cases group mean imputation was used as strategy for handling missing data. Altogether, $.01 \%$ of single missing data points were imputed, resulting in a total of 321 complete cases. Table 2 summarizes cases contingent upon respondent groups according to ECF participation and point in time. To assure robustness of results all statistical analysis were compared to a dataset based on complete case analysis.

Shapiro-Wilk tests were significant, hence the hypothesis of normal distribution of data is rejected. Inhomogeneity in variance is identified with Levene's test. Consequently, Mann-Whitney-U tests are applied for hypothesis testing.

\section{Table 2. Respondent groups}

\begin{tabular}{lcc}
\hline & Pre-ECF & Post-ECF \\
\hline Participants & $\mathrm{n}=123$ & $\mathrm{n}=99$ \\
\hline $\begin{array}{l}\text { Non-Participants } \\
\text { (control group) }\end{array}$ & $\mathrm{n}=51$ & $\mathrm{n}=48$ \\
\hline
\end{tabular}

\section{Results}

Table 3 presents the means, standard deviations and correlations for all the variables according to the respondent groups. Trait engagement as stable personality trait is assessed in the pre-ECF questionnaire only.

\section{Table 3. Means, standard deviations and correlations among the variables}

\begin{tabular}{llllll}
\hline \hline Groups and variables & Mean & SD & $\mathbf{1}$ & $\mathbf{2}$ & $\mathbf{3}$ \\
\hline \hline Pre-ECF & & & & & \\
\hline \hline Participants & & & & & \\
\hline 1 State engagement & 3.48 & 0.79 & 1 & & \\
2 Behavioral engagement & 4.25 & 0.50 & 0.11 & 1 & 0 \\
3 Trait engagement & 4.24 & 0.59 & 1 & 0.06 & 0.57 \\
& & & & & \\
\hline Non-Participants & & & & & \\
\hline 1 State engagement & 3.69 & 0.58 & 1 & 0 & \\
2 Behavioral engagement & 4.12 & 0.51 & 00.33 & 1 & \\
3 Trait engagement & 4.11 & 0.49 & 0.27 & 0.61 & 1 \\
\hline \hline Post-ECF & & & & & \\
\hline Participants & & & & & \\
\hline 1 State engagement & 3.64 & 0.79 & 1 & & \\
2 Behavioral engagement & 4.36 & 0.66 & 0.80 & 1 & \\
\hline Non-Participants & & & & & \\
\hline 1 State engagement & 3.73 & 0.69 & 1 & & \\
2 Behavioral engagement & 4.12 & 0.63 & 0.09 & 1 & \\
\hline \hline
\end{tabular}

SD: Standard deviation $\quad 1,2,3:$ Pearson correlation coefficients

Before ECF, the group of participants $(n=123)$ exhibits means of 3.48 (state engagement), 4.25 (behavioral engagement) and 4.24 (trait engagement). In turn, the group of non-participants $(n=51)$ shows means of 3.69 (state engagement), 4.12 (behavioral engagement) and 4.11 (trait engagement). After the ECF initiative, participants $(\mathrm{n}=99)$ exhibit engagement means of 3.64 (state engagement) and 4.36 (behavioral engagement) compared to 3.73 (state engagement) and 4.36 (behavioral engagement) in the group of nonparticipants $(\mathrm{n}=48)$.

Accordingly, the boxplots depicted in Figure 2 visualize the differences in distribution and variability. The boxplot visualization suggests differences in respondent groups with respect to first and third 
quartiles. Differences are especially salient in the comparison of behavioral engagement, contrasting both, participants and non-participants post-ECF as well as participants pre- and post-ECF.

\section{Pre-ECF (comparing participants and non-participants)}

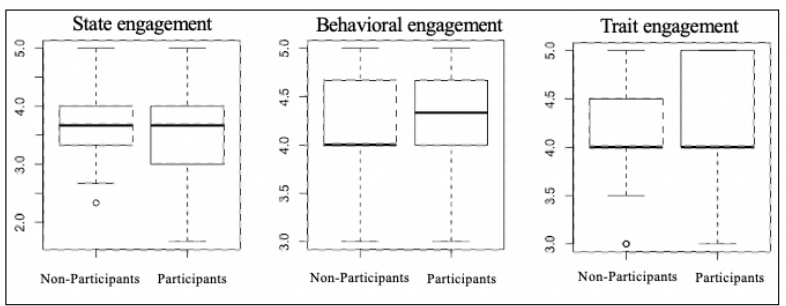

Post-ECF (comparing participants and non-participants)

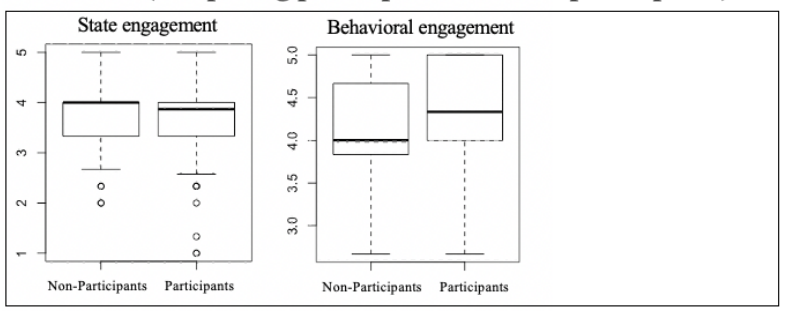

Participants (comparing pre-ECF and post-ECF)

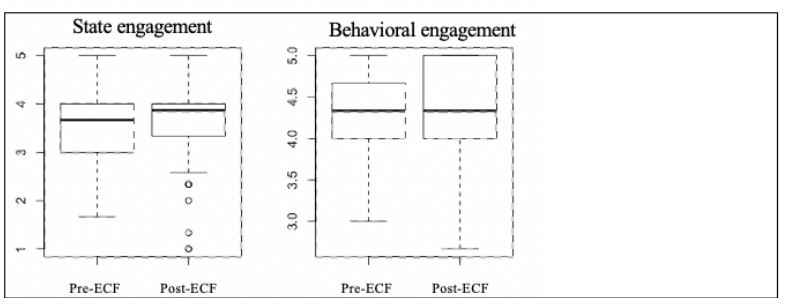

Figure 2. Boxplots

We employed Mann-Whitney-U tests to test for identity of distribution between respondent groups according to participation in the ECF initiative and point in time (Table 4). Values for behavioral engagement of participants post-ECF are significantly different $(\mathrm{p}<$ $.05)$ from those of non-participants post-ECF. Hence, after participating in enterprise crowdfunding, employees were more behaviorally engaged than members of the control group (H2b). Significant differences $(p<.1)$ can also be observed for values of participants' behavioral engagement pre- and post ECF. This suggests that participation in ECF leads to an increase in employees' behavioral engagement (H3b).

Comparing values for trait engagement, state engagement and behavioral engagement of participants and non-participants pre-ECF, no significant differences can be observed. The same applies to values of state engagement, by comparing participants and nonparticipants post-ECF as well as participants pre- and post-ECF. Consequently, our data did not provide support for hypotheses H1a, H1b, H1c, H2a and H3a.

\section{Table 4. Results of the Mann-Whitney-U test}

\begin{tabular}{lllll}
\hline \hline $\begin{array}{l}\text { Pre-ECF: Comparing } \\
\text { (NP) }\end{array}$ & Participants & (P) and & Non-Participants \\
\hline \hline & $\mathbf{M}_{\mathbf{P}}$ & $\mathbf{M}_{\mathbf{N P}}$ & $\mathbf{W}$ & $\mathbf{p}$ \\
\hline State engagement & 3.48 & 3.69 & 3458 & .28 \\
Behavioral engagement & 4.25 & 4.12 & 2672 & .11 \\
Trait engagement & 4.24 & 4.11 & 2703 & .14 \\
\hline \hline
\end{tabular}

Post-ECF: Comparing Participants (P) and Non-Participants (NP)

\begin{tabular}{lllll}
\hline \hline & $\mathbf{M P}_{\mathbf{P}}$ & $\mathbf{M}_{\mathbf{N P}}$ & $\mathbf{W}$ & $\mathbf{p}$ \\
\hline State engagement & 3.64 & 3.73 & 2540 & .49 \\
Behavioral engagement & 4.36 & 4.11 & 1815 & $.02 * *$
\end{tabular}

\begin{tabular}{lllll}
\hline \hline \multicolumn{5}{l}{ Participants: Comparing Pre-ECF and Post-ECF } \\
\hline \hline & MPre & MPost & W & p \\
\hline State engagement & 3.48 & 3.64 & 5367 & .12 \\
Behavioral engagement & 4.25 & 4.36 & 5241 & $.06 *$ \\
& & & & \\
\hline \hline & & & \\
\hline \hline
\end{tabular}

\section{Discussion}

Our study aimed at exploring how the introduction of and participation in enterprise crowdfunding affects employees' engagement. Therefore, we compared ECF participants' and non-participants' engagement before and after the ECF initiative. A summary of statistical support for research hypotheses is presented in Table 5.

\section{Table 5. Summary of statistical support for research hypotheses}

\begin{tabular}{|c|c|c|}
\hline \multicolumn{2}{|c|}{ Hypothesis } & \multirow{2}{*}{$\begin{array}{l}\text { Support } \\
\text { Not } \\
\text { supported }\end{array}$} \\
\hline H1a & $\begin{array}{l}\text { Employees deciding to participate in enterprise } \\
\text { crowdfunding initiatives exhibit lower levels of } \\
\text { state engagement compared to non-participants. }\end{array}$ & \\
\hline H1b & $\begin{array}{l}\text { Employees deciding to participate in enterprise } \\
\text { crowdfunding initiatives exhibit higher levels of } \\
\text { behavioral engagement compared to non- } \\
\text { participants. }\end{array}$ & $\begin{array}{l}\text { Not } \\
\text { supported }\end{array}$ \\
\hline H1c & $\begin{array}{l}\text { Employees deciding to participate in enterprise } \\
\text { crowdfunding initiatives exhibit higher levels of } \\
\text { trait engagement compared to non-participants. }\end{array}$ & $\begin{array}{l}\text { Not } \\
\text { supported }\end{array}$ \\
\hline H2a & $\begin{array}{l}\text { Employees who participated in enterprise } \\
\text { crowdfunding exhibit higher levels of state } \\
\text { engagement compared to non-participants. }\end{array}$ & $\begin{array}{l}\text { Not } \\
\text { supported }\end{array}$ \\
\hline H2b & $\begin{array}{l}\text { Employees who participated in enterprise } \\
\text { crowdfunding exhibit higher levels of behavioral } \\
\text { engagement compared to non-participants. }\end{array}$ & $\begin{array}{l}\text { Supported } \\
(\mathrm{p}<.05)\end{array}$ \\
\hline H3a & $\begin{array}{l}\text { Participants' state engagement increases upon } \\
\text { participation in enterprise crowdfunding. }\end{array}$ & $\begin{array}{l}\text { Not } \\
\text { supported }\end{array}$ \\
\hline H3b & $\begin{array}{l}\text { Participants' behavioral engagement increases } \\
\text { upon participation in enterprise crowdfunding }\end{array}$ & $\begin{array}{l}\text { Supported } \\
(\mathrm{p}<.1)\end{array}$ \\
\hline
\end{tabular}


Before the ECF initiative, we did not observe significant differences in participants' state engagement, behavioral engagement, or trait engagement compared to non-participants. Since, at the point of inquiry, participants were identified based on voluntary registration to the ECF initiative, this stands in contrast to our hypotheses and prior work (e.g., by Wendelken et al. [38] or Jovanovic et al. [2]. However, this could suggest that enterprise crowdfunding as specific implementation of crowd-innovation platforms and enterprise social system might be less affected by participation self-selection biases, such that only highly motivated and previously engaged employees participate. This aspect can be advantageous for companies since it indicates that ECF has relatively low barriers to participation. Thereby, diffusion and acceptance of the ECF platform among the workforce is facilitated. Furthermore, it reinforces the suitability of enterprise crowdfunding as tool to foster employee engagement: If only highly engaged employees participated anyway, such tools would further increase differences in engagement of employees. Hence, our results suggest ECF to be reasonably inclusive in terms of attracting employees regardless of their current levels of engagement.

To capture the effect of ECF participation on employee engagement, we compared both, participants pre and post ECF, and participants and the control group of non-participants post ECF. While location and dispersion measures indicate slightly increased level of state engagement and behavioral engagement after ECF participation, only differences in behavioral engagement are statistically significant $(\mathrm{p}<0.05)$. Consequently, employees, who have participated in enterprise crowdfunding are more likely to invest their personal resources (e.g., time, attention) beyond the expected demand. They are more proactive, willing to expand their role and tasks, and more motivated to adapt to organizational changes. Since enterprise crowdfunding is primarily used to foster new projects and innovation in organizations, this increase in behavioral engagement can be beneficial for the subsequent implementation phase. Following the definition of behavioral engagement, engaged employees will be more willing to drive the implementation of funded projects and accept the necessary changes that come with them. Thus, our work underpins Muller et al's [9] qualitative findings on the development of goals and motivations of employees participating in ECF initiatives and follows their call for investigations in other organizations.

Regarding changes in state engagement, our data did not provide support for the hypothesis of increased state engagement depending on ECF participation. However, we observe the gap between participants' and non-participants' state engagement to close. Before ECF, participants showed lower level of state engagement than non-participants. Figure 2 visualizes this convergence of location and dispersion parameters after the ECF initiative.

While our study provides valuable findings, some limitations have to be considered: First, data for this study is collected via an online survey, which is prone to biases. Data relies on self-report, thus, social desirability biases might occur as respondents answer according to what they believe is expected from them. Also, participation in our study was voluntary and based on self-selection, hence there might be a response bias. Second, we were able to observe effects in the field, which is beneficial for external validity, but brings along some limitations: the company's privacy regulations did not allow us to survey personal data or track respondents' answers over time. Consequently, we do not have dependent samples that would allow to track changes on individual levels. Thus, analysis is limited to the comparison of location and dispersion measures on the group level. Moreover, our findings are based on one particular enterprise crowdfunding initiative in a single organization. Depending on the organization, enterprise crowdfunding can be introduced and positioned in different ways, i.e., there are differences in the intensity of advertising or the communication of strategic importance. Equally, the platform and mechanism itself can be designed differently, i.e., there might be differences in the user interface design, in the share of budget each employee receives to invest, or in the characteristics of proposals.

These limitations, however, might provide opportunities for future research: first of all, we recommend that our research is expanded to other companies and instantiations of enterprise crowdfunding. In doing so, validity and robustness of our findings can be confirmed and strengthened. Furthermore, future research needs to deepen the understanding of underlying factors that are responsible for increasing employee engagement through ECF participation. As of now, we know that ECF has the potential to stimulate employee engagement, yet, it is still unclear which of the characteristics of ECF are responsible for this stimulation. Is it the transfer of the right to decision-making, the possibility of expressing one's opinion, the potential for collaboration, or other factors inherent to ECF that cause engagement to increase? Future research can adopt a more nuanced perspective on ECF characteristics and employee engagement, for example by altering, testing and comparing different designs of the ECF mechanism and platform. Finally, we would like to encourage future research to further follow the path of exploring internal crowd-based innovation platforms from a socio- 
economic perspective. Within this study, we focused on employee engagement as one potential spillover effect of enterprise crowdfunding. However, there are other positive effects on the organizational culture and workforce attitude-e.g., intrapreneurial culture, retention or sustaining cross-departmental collaboration - that are worth investigating.

\section{Conclusion}

With this study, we intended to expand research horizons for enterprise crowdfunding and similar internal crowd-innovation platforms by exploring them from an engagement and corporate culture perspective. In particular, we investigated how participation in an enterprise crowdfunding initiative affects employee engagement of participants. Therefore, we conducted an online survey in the context of an enterprise crowdfunding initiative at a global manufacturing and electronics corporation. Based on data from 321 participants and non-participants collected at two different points in time, we observed significant increases in employees' behavioral engagement contingent upon participation in ECF. Thereby, our study provides valuable contributions to research and practice. First, we expand knowledge on the still small field around enterprise crowdfunding. Positioned at the intersection of research on public crowdfunding and enterprise social systems, enterprise crowdfunding inhibits certain particularities that can only be observed when combining both lenses. This study in particular, opens perspectives for ECF research beyond its functional aspects of idea generation, decision-making and financing. We emphasize the socio-economic impacts of ECF by confirming impacts on employees emotional and behavioral reactions, as measured by the concept of employee engagement. In terms of practical implications, our results may broaden the view on benefits that can be gained from the internal application of crowd intelligence approaches like enterprise crowdfunding. They are eligible tools for shaping organizations' innovation capabilities and employees' engagement, accordingly. Thus, we hope our findings to further promote the introduction of enterprise crowdfunding in an increasing number of organizations.

\section{References}

[1] P. Belleflamme, T. Lambert, and A. Schwienbacher, "Crowdfunding: Tapping the right crowd," J. Bus. Ventur., vol. 29, no. 5, pp. 585-609, 2014.

[2] T. Jovanović, B. Bansemir, M. Kirchner, and K.-I. Voigt, "The Crowdfunding Idea Contest of BMW," in IAMOT 2017 Conference Proceedings, 2017.

[3] A. Simons, L. F. Kaiser, and J. Vom Brocke, "Enterprise
Crowdfunding: Foundations, Applications, and Research Findings," Bus. Inf. Syst. Eng., vol. 61, no. 1, pp. 113-121, 2019.

[4] N. Feldmann, H. Gimpel, M. Kohler, and C. Weinhardt, "Using crowd funding for idea assessment inside organizations: Lessons learned from a market engineering perspective," in 2013 International Conference on Cloud and Green Computing, 2013, pp. 525-530.

[5] T. Wang, C.-H. Jung, M.-H. Kang, and Y.-S. Chung, "Exploring determinants of adoption intentions towards Enterprise 2.0 applications: an empirical study," Behav. Inf. Technol., vol. 33, no. 10, pp. 1048-1064, Oct. 2014.

[6] V. Vuori and J. Okkonen, "Knowledge sharing motivational factors of using an intra-organizational social media platform," J. Knowl. Manag., vol. 16, no. 4, pp. 592-603, 2012.

[7] N. Feldmann, H. Gimpel, M. Muller, and W. Geyer, "Idea Assessment via Enterprise Crowdfunding: An empirical analysis of decision-making styles," in Proceedings of the Twenty Second European Conference on Information Systems (ECIS), 2014.

[8] N. Feldmann and H. Gimpel, "Financing Projects Through Enterprise Crowdfunding: Understanding the Impact of Proposal Characteristics on Funding Success," in Proceedings of the 24th European Conference on Information Systems (ECIS), 2016.

[9] M. Muller, W. Geyer, T. Soule, S. Daniels, and L.-T. Cheng, "Crowdfunding inside the Enterprise: Employee-Initiatives for Innovation and Collaboration," in Proceedings of the SIGCHI conference on human factors in computing systems, 2013, pp. 503-512.

[10] C. Benz, N. Zierau, and G. Satzger, "Not all tasks are alike: Exploring the effect of task representation on user engagement in crowd-based idea evaluation," Proc. 27th Eur. Conf. Inf. Syst., pp. 1-17, 2020.

[11] D. Chasanidou, N. Sivertstøl, and J. Hildrum, "Exploring employee interactions and quality of contributions in intra-organisational innovation platforms," Creat. Innov. Manag., vol. 27, no. 4, pp. 458-475, Dec. 2018.

[12] T. Mitra, V. Tech, and M. Muller, "Spread of Employee Engagement in a Large Organizational Network: A Longitudinal Analysis," Proc. ACM Hum.-Comput. Interact, vol. 1, no. 2, pp. 81:1-81:20, 2017.

[13] A. Richter, A. Stocker, S. Müller, and G. Avram, "Knowledge management goals revisited," Vine, vol. 43, no. 2, pp. 132-148, 2013.

[14] W. A. Kahn, "Psychological Conditions of Personal Engagement and Disengagement at Work," Acad. Manag. J., vol. 33, no. 4, pp. 692-724, 1990.

[15] W. H. Macey and B. Schneider, "The Meaning of Employee Engagement," Ind. Organ. Psychol., vol. 1, no. January, pp. 3-30, 2008.

[16] K. Kwon and T. Kim, "An integrative literature review of employee engagement and innovative behavior: Revisiting the JD-R model," Hum. Resour. Manag. Rev., vol. 30, no. 2, p. 100704, 2020.

[17] R. J. Brodie, L. D. Hollebeek, B. Juric, and A. Ilic, "Customer engagement: Conceptual Domain, Fundamental Propositions, and Implications for 
Research," J. Serv. Res., vol. 14, no. 3, pp. 252-271, 2011.

[18] G. Burtch, A. Ghose, and S. Wattal, "An Empirical Examination of the Antecedents and Consequences of Contribution Patterns in Crowd-Funded Markets An Empirical Examination of the Antecedents and Consequences of Contribution Patterns in CrowdFunded Markets," Inf. Syst. Res., vol. 24, no. 3, pp. 499519, 2013.

[19] J. A. Fehrer and S. Nenonen, "Crowdfunding networks: Structure, dynamics and critical capabilities," Ind. Mark. Manag., vol. 88, no. July, pp. 449-464, Jul. 2020.

[20] E. M. Gerber, J. S. Hui, and P.-Y. Kuo, "Crowdfunding: Why people are motivated to post and fund projects on crowdfunding platforms," Position paper at CSCW 2012 DIST workshop. Bellevue, USA, p. 10, 2012.

[21] E. Mollick, "The dynamics of crowdfunding: An exploratory study," J. Bus. Ventur., vol. 29, no. 1, pp. 116,2014

[22] O. Zuchowski, O. Posegga, D. Schlagwein, and K. Fischbach, "Internal crowdsourcing: Conceptual framework, structured review, and research agenda," $J$. Inf. Technol., vol. 31, no. 2, pp. 166-184, 2016.

[23] A. P. McAfee, "Enterprise 2.0: The Dawn of Emergent Collaboration," MITSloan Manag. Rev., vol. 47, no. 3, pp. 15-26, 2006.

[24] O. Zuchowski, K. Fischbach, D. Schlagwein, and K. Fischbach, "“ Open Calls' Rather Than " Fixed Assignments ': A Longitudinal Field Study of the Nature and Consequences of Internal Crowdsourcing," in Proccedings of the Thirty Seventh International Conference on Information Systems (ICIS), 2016.

[25] J. Surowiecki, The wisdom of crowds: why the many are smarter than the few and how collective wisdom shapes business, economies, societies and nations, XXI. New York: Anchor Books, 2004.

[26] J. M. Gómez, A. Sandau, K. Sevimli, and C. Schmitt, "Proof of concept - Enterprise Crowdfunding," in International Conference on Information Resources Management (CONF-IRM), 2016.

[27] T. Wagenknecht, T.; Teubner, and C. Weinhardt, "Peer Ratings and Assessment Quality in Crowd-Based Innovation Processes," in Proceedings of the TwentyFifth European Conference on Information Systems (ECIS), 2017, pp. 3144-3154.

[28] J. K. Harter, F. L. Schmidt, and T. L. Hayes, "Businessunit-level relationship between employee satisfaction, employee engagement, and business outcomes: A metaanalysis.," J. Appl. Psychol., vol. 87, no. 2, pp. 268-279, 2002.

[29] W. B. Schaufeli, M. Salanova, V. González-Romá, and A. B. Bakker, "The Measurement of Engagement and Burnout: A Two Sample Confirmatory Factor Analytic Approach," J. Happiness Stud., vol. 3, no. 1, pp. 71-92,
2002.

[30] M. R. Simpson, "Engagement at work: A review of the literature," Int. J. Nurs. Stud., vol. 46, no. 7, pp. 10121024, 2009.

[31] K. Breevaart, A. B. Bakker, E. Demerouti, and J. Hetland, "The Measurement of State Work Engagement A Multilevel Factor Analytic Study," Eur. J. Psychol. Assess., 2012.

[32] A. M. Saks, "Antecedents and consequences of employee engagement," J. Manag. Psychol., vol. 21, no. 7, pp. 600-619, 2006.

[33] G. Seijts and D. Crim, "What engages employees the most or, the ten C's of employee engagement," Ivey Bus. J., vol. 23, no. April, pp. 1-5, 2006.

[34] A. D. Bhappu and U. Schultze, "Implementing an Organization-sponsored Sharing Platform to Build Employee Engagement," MIS Q. Exec., vol. 17, no. 2, pp. 109-121, 2018.

[35] S. Trimi, H. Galanxhi, S. Trimi, and H. Galanxhi, "The impact of Enterprise 2.0 in organizations," Serv Bus, vol. 8, no. 3, pp. 405-424, 2014.

[36] L. B. Jeppesen and L. Frederiksen, "Why Do Users Contribute to Firm-Hosted User Communities? The Case of Computer-Controlled Music Instruments," Organ. Sci., vol. 17, no. 1, pp. 45-63, 2006.

[37] C. P.-Y. Chin, N. Evans, and K.-K. Raymond Choo, "What Influences Employees to Use Enterprise Social Networks? A Socio-Technical Perspective," in Proceedings of the Pacific Asia Conference on Information Systems (PACIS), 2015.

[38] A. Wendelken, F. Danzinger, C. Rau, and K. M. Moeslein, "Innovation without me : why employees do ( not ) participate in organizational innovation communities," R\&D Manag., vol. 44, no. 2, pp. 217236, 2014.

[39] H. Sievert and C. Scholz, "Engaging employees in (at least partly) disengaged companies. Results of an interview survey within about 500 German corporations on the growing importance of digital engagement via internal social media," Public Relat. Rev., vol. 43, no. 5, pp. 894-903, Dec. 2017.

[40] L. R. Men, J. O'Neil, and M. Ewing, "Examining the effects of internal social media usage on employee engagement," Public Relat. Rev., vol. 46, no. 2, p. 101880, 2020.

[41] H. Benbya and D. Leidner, "Harnessing Employee Innovation in Internal Crowdsourcing Platforms: Lessons from Allianz UK," in Proceedings of the Thirty Seventh International Conference on Information Systems (ICIS), 2016.

[42] C. Fornell and D. F. Larcker, "Evaluating structural equation models with unobservable variables and measurement error," J. Mark. Res., vol. 18, no. 1, pp. 39-50, 1981. 